\title{
Energy Analysis of a Coal-fired MHD Power Plant
}

\author{
Prabin Haloi, Tapan Kumar Gogoi
}

\begin{abstract}
The present work concerns with the energy analysis model of a $30 \mathrm{MW}$ coal-fired Magneto-hydrodynamics (MHD) power plant. The first law analysis is performed for the energy flow through the first three components of the plant namely the combustor, a supersonic nozzle and the MHD generator. Energy losses of the three plant components are analysed applying energy balance. Plasma conductivity is enhanced with Caesium as seed material. It has been observed that the combustion gas at combustor exit section has the highest specific enthalpy and is minimum at the exit of generator. The maximum energy loss component is the generator and is minimum for the nozzle. Similarly, the component with highest thermal efficiency is the nozzle and it is lowest in the generator. In each case the MHD combustor stands as intermediate.
\end{abstract}

Keywords : Electrical conductivity, magnetohydrodynamics, specific enthalpy, thermal efficiency.

\section{INTRODUCTION}

Growth in the gap between supply and demand especially in the fossil fuel energy resources has affected in the search for a more reliable and sustainable alternative. Non-conventional sources such solar, wind, tidal power have been harnessed to the benefits of mankind. System improvement has seen remarkable development in the power industries. High temperature turbine blades, HRSGs etc. are being developed with the advent of many newly discovered high temperature resistant materials. Notwithstanding all such developments, the use of such components have their own limitations as well. Their use is limited by the maximum temperature limit, mechanical deterioration requiring frequent maintenance and of course an added cost. The role of Magneto-hydrodynamics (MHD) is seen to outplay the performance of most of the present-day power generating systems in achieving higher temperature. The operating temperature achieved in MHD is much higher than the more advanced gas turbines. Another advantage of MHD is the absence of movable parts unlike turbine blades and hence is free from any corrosion or temperature related degradation in the long run. MHD based integrated systems [1] have been studied for performance analysis and achieved high efficiency using syngas compared to direct coal combustion. MHD research has been considered a potential area for future power generation as can be found in various literature $[1,9,11,12$, 15]. Power generation in existing plants can be enhanced [9]

Revised Manuscript Received on July 22, 2019.

Prabin Haloi, Department of Mechanical Engineering, Tezpur University, Tezpur, India.

Tapan Kumar Gogoi, Department of Mechanical Engineering, Tezpur University, Tezpur, India. Email: tapan_g@tezu.ernet.in using MHD system. Although a number of work related to different aspects of MHD operation has been performed satisfactorily, a detailed energy analysis of the complete system is yet to be attempted fully. The present work makes an energy analysis of an MHD power plant fed with pulverized coal. Preheated air is used for coal combustion for higher efficiency along with the addition of caesium as seeded material to the extent of $1 \%$ of the total of fuel and air flow rates as a practical quantity. Analysis of the preheating of combustion reactants reduces chemical energy uses [7] and improves scope for increasing lean fuel in gaseous fuel mixture.

Theoritical and experimental based investigations have been conducted on the different instrumentations of MHD governing fluid flow, electro-magnetism, high temperature material, plasma and more and is largely scattered in different forms of researches. Optimum power extraction in MHD generator have been obtained [12] using supersonic inlet where the critical interaction parameters remains passive at the exit. Thermodynamic analysis based on first and second laws have been conducted for numerous thermal power systems [5,14] as well. But a proper analysis of MHD power plant thermodynamically in terms of energy and second laws have not been undertaken as yet. Performance analysis of MHD power cycles at maximum power density [11] reports increase in MHD cycle efficiency. Ionization processes at different temperatures have been discussed [2, 4] and the dissociative behavior of molecules to form ions and electrons were elaborated. The ionization of the combustion gas molecules can occur in a number of ways [4] and study on the autoionization of diatomic molecules [3] using a two state model have found that the products of combustion gets partially ionized under high temperature where a portion of the combustion gas is ionized and the other remains as combustion unionized gas. Performance and stability of MHD generator under the effect of ionized seed plasma [13] have been studied considering varied seed fractions. The present work idealizes ionized gas as combustion gas only for convenience of analysis. Combustible ionized gas in thermal power plants has been modeled [16] using MHD conversion system to improve power generation. The degree of ionization at low temperature with the use of seed and the constituents of ionized gases that are of interest at high temperature have been illustrated [2]. Accordingly for ionized gases only the positive ions are considered. Method of thermodynamic analysis of energy systems can been found in detail [10] in which the methods of thermal design and optimization of such systems is discussed. 


\section{MODEL DESCRIPTION}

The MHD power system under consideration with its components for analysis is shown in Fig.1. which is a 30 MW-electrical coal-fired plant.

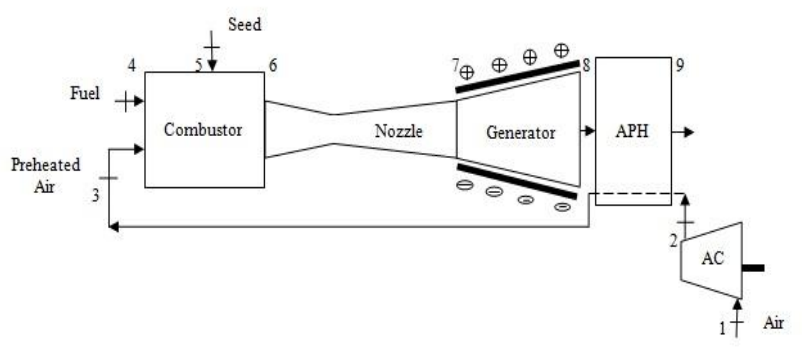

Fig. 1. Schematic of MHD power plant with air preheater and air compressor.

The plant combustor is fed with three types of input namely pulverized coal selected from Makum coal fields in Assam, preheated air upto $1800 \mathrm{~K}$ and Caesium (Cs) as seed material. The high temperature combustion gas is partially ionized under high temperature in the combustor and flows as plasma to the MHD generator after passing through a supersonic nozzle. The nozzle accelerates the working fluid resulting in a high-temperature, high velocity fluid. The MHD generator is subjected to a strong magnetic field $(B=2$ Tesla) of a superconductive magnet placed perpendicularly to the flow. The magnetic field induces an electric field that develops an electric potential across electrodes that are mounted on the generator walls transversely. The gases that exits the generator being very hot is used for air preheating. Beyond the preheater the exhaust gas still possess high thermal energy that can be useful in other downstream heat exchange components or as heating medium for power generation in gas and steam turbines. The MHD system beyond the preheater can be attached to a seed recovery unit for recovering the seed material, a desulfurization unit to remove sulphur compounds from the exhaust combustion gas before it is released to the environment which is not a part of this present analysis.

\section{A. Mathematical Formulation}

The thermodynamic model of the MHD plant follows mass and energy conservation laws applied to a component as control volume (CV) at steady state [5].

- Mass conservation equation: The inlet mass flow rate to $\mathrm{CV}$ is equal to the exit mass rate from the $\mathrm{CV}$.

$$
\sum_{\text {in }} \dot{m}_{\text {in }}=\sum_{\text {out }} \dot{m}_{\text {out }}
$$

- Energy conservation equations: For a component, the control volume idealized at steady state is given by $[5,14]$, the energy balance gives equal energy transfer rate for the flow stream entering and exiting the control volume. Neglecting the changes in kinetic and potential energy terms, the energy equation becomes

$$
\dot{Q}_{C V}+\sum_{\text {in }} \dot{m}_{\text {in }} h_{\text {in }}=\dot{W}_{C V}+\sum_{\text {out }} \dot{m}_{\text {out }} h_{\text {out }}
$$

where m's, h's are the mass flow rates and specific enthalpies at the inlet and exit of $\mathrm{CV}, \dot{Q}_{C V}$ and $\dot{W}_{C V}$ are the rates of heat and work transfer measures within the $\mathrm{CV}$. In the present model, the preheated air, coal and seed entry to the MHD combustor are at the states $3,4,5$. State 6 is the combustor exit as well as the nozzle inlet state point. For the purpose of analysis the inlet air conditions to the axial flow compressor is at state 1 where the inlet conditions are at environmental state $T_{0}=298.15 K, p_{0}=1$ bar which are also the reference state for the model.

- Combustor: The mass and energy balance equations for the MHD combustor $\mathrm{CV}$ at steady state is given by (3), (4)

$$
\begin{gathered}
\dot{m}_{6}=\dot{m}_{3}+\dot{m}_{4}+\dot{m}_{5} \\
\frac{\dot{m}_{6} h_{6}}{M_{6}}-\frac{\dot{m}_{3} h_{3}}{M_{3}}-\frac{\dot{m}_{4} h_{4}}{M_{4}}-\frac{\dot{m}_{5} h_{5}}{M_{5}}=\dot{Q}_{C V}
\end{gathered}
$$

and

The energy transfer rate $\dot{E}_{i}$ at any state 'i' of the MHD plant is obtained by the relation given in equation (5)

$$
\dot{E}_{i}=\frac{\dot{m}_{i} h_{i}}{M_{i}} \text { in } M W
$$

where, $M_{i}$ is the molecular weight of the stream at state ${ }^{\prime \prime}$

- Nozzle: The mass and energy balance equations for the supersonic nozzle $\mathrm{CV}$ at steady state is given by (6) as

$$
\dot{m}_{6}=\dot{m}_{7}
$$

and,

$$
\frac{\dot{m}_{6}\left(h_{6}-h_{7}\right)}{M_{6}}=\dot{m}_{6} \frac{v_{7}^{2}}{2}
$$

- MHD Generator: The generator in the MHD plant receives the high temperature high velocity combustion products from the nozzle. The mass and energy balance equations for the generator $\mathrm{CV}$ at steady state is obtained by (8), (9)

$$
\dot{m}_{7}=\dot{m}_{8}
$$

and,

$$
\frac{\dot{m}_{7}\left(h_{7}-h_{8}\right)}{M_{7}}=\dot{w}_{e}
$$

- Air Compressor: The air compressor is a multistage axial flow compressor. The exit air from the compressor is fed to the combustor of MHD using preheat of MHD generator exhausts. The mass and energy balance equations for the compressor $\mathrm{CV}$ at steady state is

$$
\begin{aligned}
& \dot{m}_{1}=\dot{m}_{2} \\
& \frac{\dot{m}_{1}\left(h_{1}-h_{2}\right)}{M_{1}}=\dot{w}_{\text {compressor }}
\end{aligned}
$$




\section{B. Determination of Fuel-Air Ratio, Heating Value and Mass Flow Rates}

The higher heating value (HHV) for the present Makum coal is obtained on a dry and ash free basis. The elemental composition of this Assam coal [10] (\% wt) is C: 79.11, H: 5.54, S-4.95, O-8.95, N-1.45, A-4.9 (Air dried) and moisture: 2.1, volatile matter: 45.3 on $\%$ wt. Here, the air dried basis $\%$ of $\mathrm{C}, \mathrm{H}, \mathrm{O}, \mathrm{N}, \mathrm{S}$ is taken as the dry and ash free basis for analysis. On the other, from the air molar analysis the composition of air is $\mathrm{N}_{2}: 77.51 \%, \mathrm{O}_{2}: 20.62 \%, \mathrm{CO}_{2}: 0.03 \%$ and $\mathrm{H}_{2} \mathrm{O}: 1.84 \%$.

- Coal-Air Combustion Reaction Equation: The dry and ash free pulverized coal at $T_{0}, p_{0}$ reacts with the preheated air to produce partially ionized product.

$a C+b H+c O+d N+e S+\left[0.7751 N_{2}+0.2062 \mathrm{O}_{2}+0.0003 \mathrm{CO}_{2}+0.0184 \mathrm{H}_{2} \mathrm{O}\right]$

$\rightarrow x_{\mathrm{N}_{2}} \mathrm{~N}_{2}+x_{\mathrm{O}_{2}} \mathrm{O}_{2}+x_{\mathrm{CO}_{2}} \mathrm{CO}_{2}+x_{\mathrm{H}_{2} \mathrm{O}} \mathrm{H}_{2} \mathrm{O}+x_{\mathrm{SO}_{2}} \mathrm{SO}_{2}$

where a, b, c, d, e are the \% mass fractions (in $\mathrm{kmol} / \mathrm{kg}$ ) of coal constituents and the $x_{k}{ }^{\prime} s$ on the right hand side of equation (12) are the mole fractions of the products of combustion.

The fuel-to-air ratio is computed to be 0.07321 . HHV of coal is obtained using expression of [13] which is given as

$$
H H V=[152.19 H+98.767]\left[\frac{C}{3}+H-\frac{O-S}{8}\right]
$$

where $\mathrm{C}, \mathrm{H}, \mathrm{O}, \mathrm{N}, \mathrm{S}$ denotes the $\%$ mass fraction of elements in coal. The mass flow rate of air at the states 1,2,3 are taken as constant assuming constant air properties and are estimated from the relation of [5] once the specific enthalpies for the air compressor and that of the generator has been found. The fuel flow rate is first estimated considering combustion efficiency of 0.9 and a conversion efficiency of 0.35 and determining the heat rate to obtained coal flow rate at state 4 for the desired output.

$$
\dot{m}_{4}=F \frac{M_{4}}{M_{1}} \times \dot{m}_{1}
$$

and at states 6, 7, 8 are obtained from (3), (6) and (8) respectively.

Table- I: Mass and mole fractions of reactants and products

\begin{tabular}{ccccccc}
\hline & $\begin{array}{c}\text { Mass fractions \% } \\
\text { (dry and ash free) }\end{array}$ & \multicolumn{5}{c}{ Mole fractions } \\
\hline $\begin{array}{c}\text { Coal } \\
\text { Speci } \\
\text { es }\end{array}$ & $\begin{array}{c}\text { Mass } \\
\text { fraction } \\
(\%)\end{array}$ & $\begin{array}{c}\text { Mass } \\
\text { fraction } \\
(\text { kmol/kg })\end{array}$ & $\begin{array}{c}\text { Air } \\
\text { species }\end{array}$ & $\begin{array}{c}\text { Mole } \\
\text { fraction }\end{array}$ & $\begin{array}{c}\text { Product } \\
\text { species }\end{array}$ & $\begin{array}{c}\text { Mole } \\
\text { fraction }\end{array}$ \\
\hline $\mathrm{C}$ & 79.11 & 0.065925 & $\mathrm{~N}_{2}$ & 0.7751 & $\mathrm{~N}_{2}$ & 0.77561 \\
$\mathrm{H}$ & 5.54 & 0.055400 & $\mathrm{O}_{2}$ & 0.2062 & $\mathrm{O}_{2}$ & 0.20900 \\
$\mathrm{O}$ & 8.95 & 0.005600 & $\mathrm{CO}_{2}$ & 0.0003 & $\mathrm{CO}_{2}$ & 0.06622 \\
$\mathrm{~N}$ & 1.45 & 0.001036 & $\mathrm{H}_{2} \mathrm{O}$ & 0.0184 & $\mathrm{H}_{2} \mathrm{O}$ & 0.04610 \\
$\mathrm{~S}$ & 4.95 & 0.001550 & - & - & $\mathrm{SO}_{2}$ & 0.00155 \\
\hline
\end{tabular}

\section{Specific enthalpies, pressure and temperature}

The values for specific enthalpies at states 1 to 8 are obtained using enthalpy relations [5] with respect to type and composition of the material streams at a given state point. The

specific enthalpies being a function of temperature depend on the state temperature and are obtained mostly by interpolating the values given by [6] and JANAF Thermochemical Properties Tables.

For

$$
h_{\text {air }}(T)=\left[x_{\mathrm{N}_{2}}^{*} h_{\mathrm{N}_{2}}+x_{\mathrm{O}_{2}}^{*} h_{\mathrm{O}_{2}}+x_{\mathrm{CO}_{2}}^{*} h_{\mathrm{CO}_{2}}+x_{\mathrm{H}_{2} \mathrm{O}}^{*} h_{\mathrm{H}_{2} \mathrm{O}}\right](T)
$$

where the asterisk terms denote mole fractions of air constituents.

With air compressor pressure ratio of 10 , the temperature and pressure at state 2 and specific enthalpy values at states 1 and 2 are estimated.

For the fuel and combustion product the specific enthalpies are found in a similar way as given by equation (16).

$$
h_{k}=X_{i} \sum h_{i}(T)
$$

where $X_{i}, h_{i}$ are the $\%$ mass fractions of coal species and specific enthalpy of species $i$ at temperature T.

$$
h_{6.7 .8}=x_{\mathrm{N}_{2}}^{m} h_{\mathrm{N}_{2}}+x_{\mathrm{O}_{2}}^{\mathrm{m}} h_{\mathrm{O}_{2}}+x_{\mathrm{CO}_{2}}^{\mathrm{m}} h_{\mathrm{CO}_{2}}+x_{\mathrm{H}_{2} \mathrm{O}}^{\mathrm{m}} h_{\left.\mathrm{H}_{2}\right)}+x_{\mathrm{SO}_{2}}^{\mathrm{m}} h_{\mathrm{SO}_{2}}
$$

where $\mathrm{m}$ superscripts terms denotes the mole factions of fractions of the combustion products.

Temperatures at states 1,4 and 5 are those of the reference state. At state 3 the preheat air temperature is fixed conveniently and at 6 the temperatures correspond to that of the constant-pressure adiabatic flame temperature in combustor which is conveniently chosen considering added Cs seed. The pressure at state 3 corresponds to compressor exit pressure with a 5\% air-side pressure drop in the air-preheater and $4 \%$ in generator.

Table- II: Temperature, pressure, mass flow rates and specific enthalpies at state points

\begin{tabular}{ccccr}
\hline State & \multicolumn{1}{c}{$\mathbf{T}$} & $\begin{array}{c}\mathbf{p} \\
(\mathbf{K})\end{array}$ & $\begin{array}{c}\dot{\boldsymbol{m}} \\
(\mathbf{k g} / \mathbf{s})\end{array}$ & $\begin{array}{c}\text { h } \\
(\mathbf{M J} / \mathbf{k m o l})\end{array}$ \\
\hline 1 & 298.15 & 1.0000 & 86.683100 & -4.5680 \\
2 & 621.00 & 10.0000 & 86.683100 & 4.8204 \\
3 & 1800.00 & 9.5000 & 86.683100 & 43.8696 \\
4 & 298.15 & 1.0000 & 2.828500 & 621.9000 \\
5 & 298.15 & 1.0000 & 0.895116 & 76.5000 \\
6 & 4767.00 & 20.0000 & 91.301832 & 119.4520 \\
7 & 2979.20 & 2.6133 & 91.301832 & 52.9260 \\
8 & 1862.00 & 2.5090 & 91.301832 & 12.5804 \\
\hline
\end{tabular}

The pressure, temperature and velocity at the nozzle exit are obtained idealizing the nozzle flow as isentropic at exit mach number 2.0.

\section{Thermal efficiency of the MHD components}

The thermal efficiencies of the components can be determined considering the input-output relations for the component control volume. The rate of energy loss in MHD components and the energy input rate are obtained using the appropriate relations from (3) to (17).

$$
\eta_{I}=\frac{\text { output }}{\text { input }}=1-\frac{\dot{E}_{\text {loss }}}{\dot{E}_{\text {in }}}
$$

Hence the overall efficiency of the system is calculated as $\eta_{0}=\frac{\sum \dot{E}_{\text {out }}}{\sum \dot{E}_{\text {in }}}$ 
Heat input of combustor is estimated from HHV and fuel flow rate from (20)

$$
\dot{Q}_{\text {in }}=\dot{m}_{\text {fuel }} \times H H V
$$

Table- III: Thermal efficiency and energy loss rate of MHD plant components

\begin{tabular}{llrrrr}
\hline Components & $E_{\text {in }}(M W)$ & $E_{\text {out }}(M W)$ & $E_{\text {loss }}(M W)$ & $\eta_{I}(\%)$ & $\eta \oplus 000$ \\
\hline Combustor & 366.27900 & 338.196433 & 28.08355 & 70.5124 & \\
Nozzle & 338.19644 & 332.189300 & 6.00715 & 96.8107 & 8 \\
Generator & 149.84430 & 65.617900 & 84.22640 & 64.3820 & \\
\hline
\end{tabular}

\section{RESULTS AND DISCUSSION}

The energy transfer rate for each of the state points 1 to 8 and the rate of energy loss for the three MHD system components are estimated from (3) to (9) along with the tabulated values of Table-II. The first law or thermal efficiency for the three components in the present analysis are obtained using the values given by (3) to (9) with the inclusion of (10) and (11) when the air compressor is also considered.

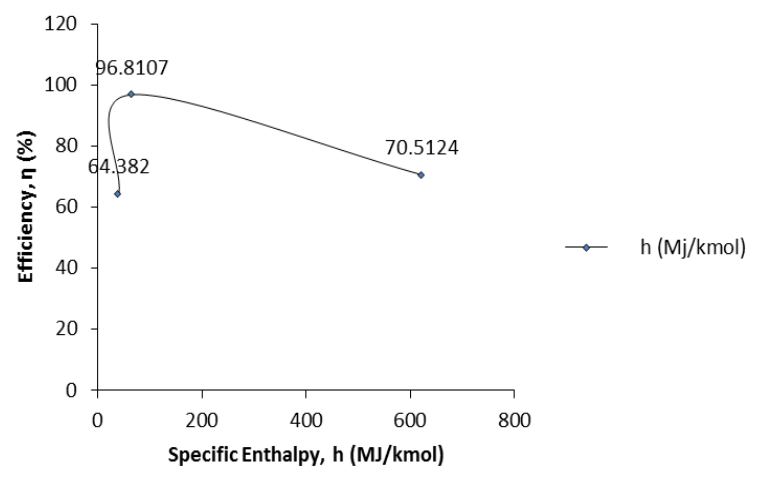

Fig. 2.Thermal efficiency with specific enthalpy variation.

The total specific enthalpy change for the combustor is found to be highest and least for the generator about 40.35 $\mathrm{MJ} / \mathrm{kmol}$. On the otherway, Fig. 2. shows that the nozzle has the highest efficiency value despite with a low value of specific enthalpy change. It is observed that efficiency of the components are not directly affected by the specific enthalpies difference between the inlet and exit sections of a component.

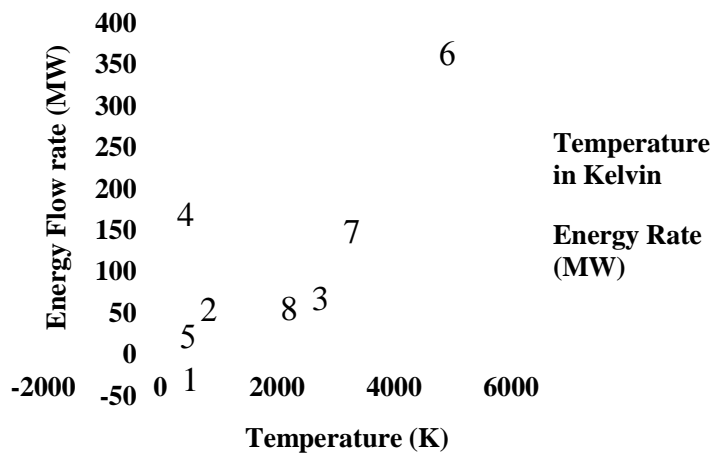

Fig. 3. Variation of energy transfer rate with temperature at different states in the MHD system.
From Fig. 3. it is estimated that for air flow, the energy transfer rate increases with an increase in temperature from states 1 to 3 . At the same time it can be stated that the state energy rate is also dependent of the stream composition as can be observed at states 4 and 5 where fuel and seed are at same constant temperature. States 6 to 8 shows a decline in energy rate with subsequent fall in temperature having same nQOB)position of flow stream.

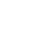

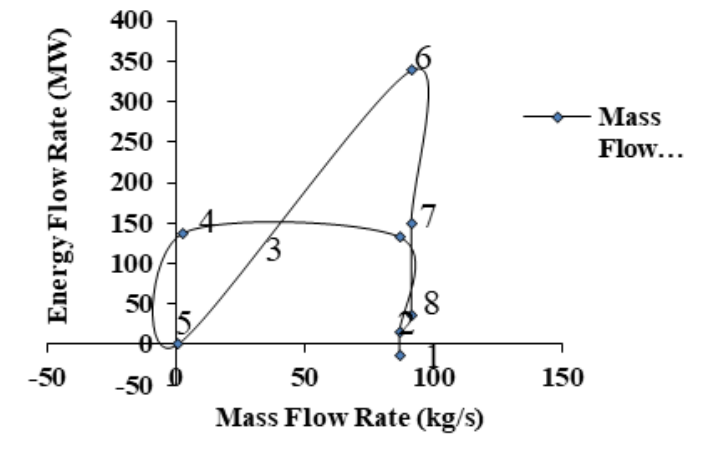

Fig. 4. Variation in rate of energy flow with mass flow rate.

From Figs. 3. and 4 and referred to Table- II it is observed that the energy flow rate increases at constant mass flow rate of air from states 1 to 3 . It increases at state 4 for reduced mass flow rate of coal and is lowest for seed at the lowest mass flow rate. From states 6 to 8 , at constant higher mass flow rate the energy rate decreases having a minimum value at state 8 . Thus it can be said that at constant mass flow rate for air and combustion products the energy flow rates is a function of temperature and specific enthalpies at given state.

While analysis the magnetohydrodynamics or MHD power generation system, only three components are evaluated for comparison in terms of their energy losses and thermal efficiencies. It has been observed that by considering the air compressor the overall efficiency of the plant drops by more than $1 \%$ due to the fact that inclusion of compressor resulted in a change in total energy input and output of the system. Moreover, in terms of thermal efficiency, the compressor turns out to be the least efficient and its efficiency is below the MHD generator, though nozzle remains the most efficient component in the plant.

The results of the present analysis can be pointed as:

1) Difference in specific enthalpy value do not affect component efficiency directly as energy calculations involves mass flow rate and molecular weights of fluid at given state.

2) Energy flow rate also depends upon temperature and fluid composition. Keeping any one fixed, the value for energy flow varies with changes in the other.

3) At constant mass flow rate, the energy transfer rate The overall plant efficiency drops when the compressor efficiency is taken in account affecting the total inflow and outflow of energy transfer.

4) The nozzle remains the most efficient component irrespective of inclusion of air compressor and air preheater. 


\section{CONCLUSION}

The energy analysis of MHD system has pointed the most and least efficient components thermally. At the same time inclusion of other components has affected the overall plant efficiency through their energy inflow and outflows. A correct estimation on performance can be achieved once the entire plant components were considered together with the application of second law of thermodynamics that will provide a better comparisons of energy transfer and efficiency.

\section{APPENDIX}

$\begin{array}{cll}\text { Symbol/Abbr } & \text { Description } & \text { unit } \\ \text { HHV } & \text { Higher heating value } & \text { MJ/kg } \\ \mathrm{T}(\mathrm{K}) & \text { Temperature } & \text { Kelvin } \\ \dot{m} & \text { Mass flow rate } & \mathrm{kg} / \mathrm{sec} \\ \mathrm{p} & \text { pressure } & \mathrm{bar} \\ Q_{c v} & \text { Heat input to control volume } & \mathrm{kJ} / \mathrm{kg} \\ W_{c V} & \text { Work done } & \mathrm{kJ} / \mathrm{kg} \\ E_{\text {loss }} & \text { Energy loss rate } & \mathrm{MW} \\ \mathrm{h} & \text { Molar specific enthalpy } & \mathrm{kJ} / \mathrm{kmol} \\ E_{\text {in }} & \text { Energy input rate } & \text { MW } \\ E_{\text {out }} & \text { Energy output rate } & \text { MW } \\ \eta_{T} & \text { Thermal efficiency } & \text { dimensionles } \\ & & \mathrm{s}\end{array}$

\section{ACKNOWLEDGMENT}

The authors of this work are thankful to all the authors, writers, co-authors for their knowledge contributions to literature whose work on different aspects of MHD has always been an inspiring source to further our research.

\section{REFERENCES}

1. P.S. Cicconardi, A. Perna, "Performance Analysis of Integrated Systems Based on MHD Generators," Energy Procedia, vol. 45, 2014, pp. 1305-1314.

2. K. Shuler, J. Fenn, "Ionization in High Temperature Gases," Progress in Astronautics \& Aeronautics, vol. 12, 1963, pp. 5-65.

3. G. Raseev, B. Leyh, L.H. Brion, “Autoionization in diatomic molecules: An example of electrostatic autoionization in $\mathrm{CO}$ atoms, molecules and clusters," vol. 2, Springer-Verlag, 1986, pp. 319-326.

4. A. Fridman, Plasma Chemistry. $1^{\text {st }}$ ed. New York: Cambridge University Press, 2008.

5. A. Bejan, G. Tsatsaronis, G, M. Moran, Thermal Design and Optimization. New York: John Wiley \& Sons Inc, 1996.

6. S.R. Turns, An Introduction to Combustion Concepts and Applications. 3rd ed. India: McGraw Hill Education Private Limited, 2012.

7. J. Szargut, "Energy and exergy analysis of the preheating of combustion reactants," Int. J. Ener. Rsrch, vol. 12, 1988, pp. 45-58.

8. T. Murakami, Y. Nakata, Y. Okuno, and H.Yamasaki, "An analytical study of the plasma conditions and performance of an MHD generator," Electrical Engineering in Japan. vol. 144, 2003, pp. 9-15.
9. R. Poonthamil, S. Prakash, and A.K. Varma, "Enhancement of power generation in thermal power plant using MHD system," IOSR J. Mech. Civ. Engg, vol.13, 2016, pp. 142-146.

10. P.K. Baruah, M.K, Baruah, "Sulphur in Assam coal," Fuel Proc. Tech, vol. 46, 1996, pp. 83-97.

11. B. Sahin, K. Ali, and Y. Hasbi, “A performance analysis for MHD power cycles operating at maximum power density," J.Phys. D. Appl. Phys, vol. 29, 1996, pp. 1473-1475.

12. S.M. Aithal, "Characteristics of optimum power extraction in a MHD generator with subsonic and supersonic inlets," Enrgy. Conv. Mgmt, vol. 50, 2009, pp. 765-771.

13. W. Eiserman, P. Johnson, and W.L. Conger, "Estimating thermodynamic properties of coal, char, tar and ash. Fuel Proc. Tech, vol. 3, 1980, pp. 39-53.

14. T.J. Kotas, The Exergy Method of Thermal Plant Analysis. London: Exergon Publishing Company UK Ltd, 2012.

15. A. R. Krishnan, and B.S. Jinshah, " Magnetohydrodynamics power generation,” Int. J. Sc. Rsrch. Pubs, vol. 3, 2013, pp. 1-11.

16. A.O. Ayeleso, and Md. T.E. Kahn, "Modelling of a combustible ionised gas in thermal power plants using MHD conversion system in South Africa," J. King Saud Univ.-Science, vol. 30, 2018, pp. 367-374.

\section{AUTHORS PROFILE}

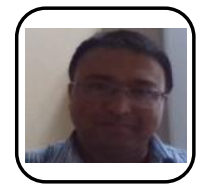

Prabin Haloi is serving as an Assistant Professor in the Department of Mechanical Engineering, Tezpur University, Tezpur, Assam and pursuing his $\mathrm{PhD}$ in Mechanical Engineering at the same Institute. His area of research interest includes Magneto-hydrodynamics power generation systems and thermal engineering. He has presented research work in a number of national and International conferences and has publications in both proceedings and journals. He has also supervised M.Tech Thesis work besides guiding a number of B.Tech projects.

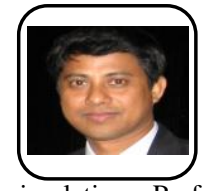

Tapan Kumar Gogoi is a Professor in the Department of Mechanical Engineering, Tezpur University, Tezpur, Assam. He is an active researcher with research interest in thermal engineering systems, biodiesel etc., their numerical analysis, mathematical coding and simulations. Professor Gogoi has presented a number of research articles in Internationally reknowned conferences including ASME. He has presented his research work in international conferences held in Sweden and U.S.A. He has also delivered a number of invited talks in reputed institutes in India. He has number of international journal publications in reputed journals including Elsevier, ASME nad more to his credit. He was a principal investigator in a number of DST-SERB research projects. He has successfully guided a number a PhD scholars besides supervising a number of M.Tech thesis work. Professor Gogoi has also served as an external examiner in recruitment in national organisations. 